\title{
The Timing Of Equity Mean Reversion In Relation To The Global Economic Cycle
}

Heng-Hsing Hsieh, PhD, CFA, University of the Western Cape, South Africa Kathleen Hodnett, PhD, University of the Western Cape, South Africa

\begin{abstract}
Investor overreaction results in the systematic overshooting of stock prices and their subsequent mean reversion. International studies on the overreaction hypothesis generally find that the mean reversion of stock returns take place after a consistent winning or losing trek for over 36 months. We construct monthly-rebalanced prior 36-month winner and loser portfolios from global equities and examine their characteristics over the period from 1999 to 2009. Using the residual returns from the capital asset pricing model (CAPM) and the 3-factor model of Fama and French (1993) as proxies for monthly abnormal returns, it is found that the loser portfolio accumulates abnormal returns mainly during turbulent times while the winner portfolio accumulates abnormal returns mainly during the upswing of the economic cycle. The resilient nature of the loser portfolio in the downswing of the economic cycle suggests that investments in past long-term losers could be regarded as a safe haven during financial market turmoil. In line with the prior study results conducted on South African stocks, the abnormal returns between the winner and loser portfolios are negatively correlated and the winner-loser spreads are found to be cyclical in relation to the economic cycle for global equities as investor sentiments and future prospects change.
\end{abstract}

Keywords: Overreaction Hypothesis; Mean Reversion; Market Timing; Contrarian; Momentum; Economic Cycle; Global Equities; Market Anomalies; The Efficient Market Hypothesis (EMH)

\section{INTRODUCTION}

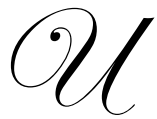

nder the notion of the efficient market hypothesis $(\mathrm{EMH})$, asset prices accurately reflect their intrinsic value instantaneously as new information arrives to the marketplace. In the presence of investor overreaction, mean reversion is required to correct over- and under-stated asset prices in order to restore equilibrium. Empirical studies generally find mean reversion to occur for stocks that consistently outperform or underperform the market for a period of 36 months or longer.

In an attempt to test the overreaction hypothesis on the JSE Securities Exchange for South African equities, Hsieh and Hodnett (2011) conclude that there exists specific market timing for mean reversion in relation to the South African economic cycle. More specifically, past long-term losers seem to outperform past long-term winners during turbulent times. Motivated by this insight, this paper tests the timing of the mean reversion for global equities in relation to the global economic cycle.

We construct global winner and loser portfolios based on the prior 36-month returns of global equities and analyze their risk-adjusted performances over the period from 1999 to 2009. The two drastic market crashes over the examination period include the crash of the information technology (I.T.) bubble in early 2000s and the sub-prime crisis that led to the financial market crash in 2008. Observing the risk-return characteristics and the performances of the global winner and loser portfolios, along with the global economic cycle over this period, provides insights into the effects of changing investor sentiments and future prospects on the timing of mean reversion for global equities.

The abnormal returns for the global winner and loser portfolios are measured as the regression residuals obtained from the capital asset pricing model (CAPM) and the 3-factor model of Fama and French (1993). Following the methodology of Hsieh and Hodnett (2011), we analyze the correlation matrix of the returns on the 
winner and loser portfolios. Their respective abnormal returns are then analyzed in order to detect the existence of specific timing for mean reversion in the global equity market. The time-series of the cumulative residual returns and the winner-loser spread are examined along with the global economic cycle in order to determine the timing of mean reversion for global equities over the examination period.

\section{LITERATURE REVIEW}

De Bondt and Thaler (1985) propose the overreaction hypothesis, stating that investors overreact to the arrival of new information, which results in systematic overshooting of asset prices. The authors argue that investors often overweigh the most recent information and underweigh the long-term fundamentals. In the presence of investor overreaction, the mean reversion of asset prices must occur in a later stage in order to restore market equilibrium.

De Bondt and Thaler (1985) test the overreaction hypothesis on the New York Stock Exchange (NYSE) over the period from 1933 to 1982. They form winner and loser portfolios based on their prior returns. Test results indicate that the loser portfolio constructed based on the prior 36-month returns outperforms the market proxy. On the other hand, the winner portfolio constructed based on the prior 36-month returns underperforms the market proxy. The degree of outperformance for the loser portfolio (measured by the average cumulative abnormal returns) is substantially greater than the degree of underperformance for the winner portfolio. The overreaction hypothesis is in direct contradiction to the EMH, which states that asset prices accurately reflect their intrinsic worth.

De Bondt and Thaler (1987) re-evaluate the validity of the overreaction hypothesis by clarifying possible biases affecting test results such as market risk, firm size and seasonality. Test results support the results of their 1985 study in that the phenomenon of mean reversion could not be explained by market risk and firm size. However, they find that abnormal returns in January and prior December seem to be negatively correlated.

Chan (1988) test the overreaction hypothesis on the NYSE over the period from 1933 to 1985 . The author argues that abnormal returns for the winner and loser portfolios are attributable to the fact that the beta coefficient of the loser portfolio increases while the beta coefficient of the winner portfolio decreases after portfolio formation.

Chopra, Lakonishok and Ritter (1992) argue that firm size, beta and prior returns are generally interrelated and each of these effects on asset pricing cannot be examined in isolation. They analyze the abnormal returns for winners and losers on the NYSE over the period from 1931 and 1986. The results indicate that the degree of mean reversion is stronger for smaller firms as more established firms that are held mainly by institutional investors are less likely to be influenced by investor overreaction. Fama and French (1993) include the proxies for the small firm effect and the value effect, in addition to the market risk premium in the CAPM, in an attempt to explain portfolios formed based on empirical anomalies. They find that the abnormal returns of long-term winners and losers, among other anomalies, are explained by the 3-factor model for U.S. stocks over the period from 1963 to 1990.

International evidence on investor overreaction includes tests conducted by Schiereck, De Bondt and Weber (1999) who find that the loser portfolios formed by prior 36-, 48- and 60-month returns outperform the DAX index on the Frankfurt Stock Exchange (FSE) over the period from 1961 to 1991; Forner and Marhuenda (2003) who find significant abnormal returns accumulated by the loser portfolio formed based on prior 60-month returns on the Spanish Stock Exchange over the period from 1963 to 1997; and Page and Way (1992) who find that the loser portfolio formed by prior 36-month returns outperform their winner counterpart for South African stocks listed on the JSE Securities Exchange (JSE) over the period from 1974 to 1989. The results of Page and Way (1992) are later verified by Muller (1999) and Hsieh and Hodnett (2011).

Hsieh and Hodnett (2011) argue that the timing of mean reversion could be cyclical and related to investor sentiments and future prospects of the economy. They form winner and loser portfolios based on 12-, 36- and 60month prior returns on the JSE over the examination period from 1993 to 2009. Test results suggest that the degree of mean reversion is strongest for the winner and loser portfolios formed based on prior 60 -month returns. The correlation analysis indicates that although the winner and loser portfolio returns are positively correlated with each other, their abnormal returns are negatively correlated. This finding implies that the winner and loser portfolios 
accumulate abnormal returns at different times. Using the loser-winner spread to indicate the profitability of a reverse relative strength strategy, the specific timing of mean reversion is determined along with the fluctuations in the South African economic cycle. More specifically, the authors find that the timing of mean reversion tends to be strongest immediately after the market crash. Test results also reveal that the loser portfolio is relatively more resilient during economic turmoil.

\section{RESEARCH METHODOLOGY}

The Dow Jones (DJ) Sector Titans Composite Index is adopted as the research database in order to gain sufficient sector exposures in the global equity market. This database covers the top 30 stocks in terms of the U.S. dollar market capitalization in each of the 19 second tier sectors defined by the Industry Classification Benchmark (ICB). These sectors include automobiles and parts, banks, basic resources, chemicals, construction and materials, financial services, food and beverages, healthcare, industrial goods and services, insurance, media, oil and gas, personal and household goods, real estate, retail, technology, telecommunication, travel and leisure and utilities. Studies conducted on large global stocks partially mitigate the effect of survivorship bias in that large established firms are less likely to be non-survivors.

The DJ Sector Titans Composite Index also offers sufficient coverage of global equities from both developed and developing markets, which include Australia, Germany, Belgium, Brazil, Canada, Denmark, Spain, Finland, France, Greece, Hong Kong, Ireland, Italy, Japan, Korea, Luxembourg, Mexico, Netherlands, Norway, Portugal, South Africa, Sweden, Singapore, Switzerland, Taiwan, the United Kingdom and the United States of America (U.S.).

The historical total return indexes of the 570 constituents comprising the DJ Sector Titans Composite Index as of 30 June 2001 are downloaded from DataStream International database. The global winner and loser portfolios are constructed by selecting the top 50 stocks and the bottom 50 stocks based on their past 36-month returns calculated using Equation 1:

$R(36 \text { prior })_{i, t}=\frac{T R_{i, t-1}}{T R_{i, t-37}}-1$

Where:

$R(36 \text { prior })_{i, t} \quad$ is the prior 36-month total return for stock $i$ at the beginning of month $t$; and

$T R_{i, t-x} \quad$ is the total return of stock $i$ in month $t-x$.

Calculating prior 36-month returns from the total return index takes into account both the capital appreciation of stock prices and dividend yield. The global winner and loser portfolios are rebalanced monthly at the beginning of each month over the examination period from 01 January 1999 to 31 December 2009. Adopting the argument of Hsieh and Hodnett (2011), the constituents of the global winner and loser portfolios are equallyweighted to avoid the capitalization drag inherent in the capitalization-weighted index. ${ }^{1}$

Hsieh and Hodnett (2011) compute the monthly abnormal returns of the global winner and loser portfolios from their excess market returns. This approach assumes a constant market risk for all portfolios. We improve the accuracy of the abnormal return estimates by computing the monthly abnormal returns from the monthly residuals of the capital asset pricing model (CAPM) and the 3-factor model of Fama and French (1993) using the Morgan Stanley Capital International (MSCI) World Index as the market proxy and the 3-month U.S. Treasury bill as the risk-free proxy. The CAPM and the 3-factor model of Fama and French (1993) are shown in Equation 2 and Equation 3 respectively:

\footnotetext{
${ }^{1}$ Hsu (2006) argues that the cap-weighted index acquires overvalued stocks and sells undervalued stocks during portfolio rebalancing in the presence of investor overreaction. This is known as the capitalization drag in the portfolio. By constructing equally-weighted winner and loser portfolios from global equities, the capitalization drag is removed from the research.
} 
$r_{P, t}-r_{f, t}=\alpha_{P}+\beta_{P} \times\left(r_{m, t}-r_{f, t}\right)+\varepsilon_{P, t}$

Where:

$\alpha_{P} \quad$ is the regression intercept representing consistent abnormal returns earned by portfolio $P$;

$r_{P, t} \quad$ is the return on portfolio $P$ in month $t$;

$r_{f, t} \quad$ is the return on the 3-month U.S. Treasury bill in month $t$;

$r_{m, t} \quad$ is the U.S. dollar total return on the MSCI World Index in month $t$;

$\beta_{P} \quad$ is the beta coefficient of the regression measuring the sensitivity of portfolio $P$ 's returns to movements in the market risk premium; and

$\varepsilon_{P, t} \quad$ is the regression residual representing the abnormal return of portfolio $P$ in month $t$.

$r_{P, t}-r_{f, t}=\alpha_{P}+\beta_{P} \times\left(r_{m, t}-r_{f, t}\right)+s_{P} S M B_{t}+h_{P} H M L_{t}+\varepsilon_{P, t}$

Where:

$s_{i} \quad$ is the sensitivity of portfolio $P$ 's return to movements in the size risk premium $S M B$; and

$h_{i} \quad$ is the sensitivity of portfolio $P$ 's return to movements in the value risk premium $H M L$.

The size risk factor, $S M B$, is estimated by the spread between the returns of the small and large firm portfolios. On the other hand, the value risk factor, $H M L$, is computed from the spread between the returns of the high book-to-market and low book-to-market portfolios. The small and large firm portfolios are constructed by selecting the largest and the smallest 50 firms based on their market capitalization at the beginning of each month over the examination period. Similarly, the high and low book-to-market portfolios are constructed by selecting 50 firms with the highest and the lowest book-to-market ratio at the beginning of each month over the examination period. These risk proxies are rebalanced monthly using the equal-weighting method.

This approach takes into account the fact that the global winner and loser portfolios might have different degrees of sensitivity to movements in the market proxy (measured by the beta coefficient). If this was the case, the abnormal returns of the winner and loser portfolios calculated by subtracting the market return from the portfolio return would be biased. The scenario that the global winner and loser portfolios have different beta coefficients is quite probable since the rolling beta coefficients for the relative strength strategy fluctuates over time as suggested in the study conducted by Hsieh and Hodnett (2011).

The regression intercept $\alpha_{p}$, in Equation 2, known as Jensen's alpha, measures the return that portfolio $P$ earned in excess of its required rate of return implied by the CAPM. In addition to Jensen's alpha, the global winner and loser portfolios are evaluated on a risk-adjusted returns basis using the Sharpe ratio and the Treynor measure as shown in Equation 4 and Equation 5 respectively:

$$
\begin{aligned}
& \text { Sharpe }_{P}=\frac{R_{P}-R_{f}}{\sigma_{P}} \\
& \text { Treynor }_{P}=\frac{R_{P}-R_{f}}{\beta_{P}}
\end{aligned}
$$

Where:

$R_{P} \quad$ is the average monthly return on portfolio $P$;

$R_{f} \quad$ is the average monthly return on the 3-month U.S. Treasury bill;

$\sigma_{P} \quad$ is the monthly standard deviation of return on portfolio $P$; and

$\beta_{P} \quad$ is the beta coefficient obtained from Equation 2. 


\section{EMPIRICAL FINDINGS}

Table 1 demonstrates the risk-return characteristics of the global winner and loser portfolios and the MSCI World Index. The basic performance statistics are shown in Panel A and the risk-adjusted performance measures are shown in Panel B. The regression results for the 3-factor model of Fama and French (1993) is demonstrated in Panel C. The $t$-statistics are shown in parentheses. Both the winner and loser portfolios outperform the MSCI World Index over the examination period in terms of their average monthly returns in Panel A. The beta coefficients and the standard deviations of both winner and loser portfolios are substantially higher than that of the MSCI World Index over the examination period. The higher risk taking of the winner and loser portfolios are justified for the market risk in that both the winner and loser portfolios outperform the MSCI World Index in terms of all three risk-adjusted performance measures (refer to Panel B). The $t$-statistics for Jensen's alpha of the winner and loser portfolios are both significant at a $5 \%$ level as shown in parentheses.

When the performances of the global winner and loser portfolios are evaluated by the 3 -factor model of Fama and French (1993), the intercept representing the size of the abnormal returns for the global winner portfolio remains statistically significant (refer to Panel C). An examination of the coefficients of the regression indicates that the returns of the global winner portfolio are positively correlated with the market risk premium and the small firm effect, but negatively correlated with the value effect. On the other hand, the abnormal return for the global loser portfolio becomes insignificant once the small firm effect and the value effect are accounted for. The returns for the global loser portfolio are positively correlated with the market risk premium, the small firm effect and the value effect. Overall, all the factors in the 3-factor model of Fama and French (1993) contribute to the explanation of the variations in the global winner and loser portfolio returns. However, the model fails to explain the abnormal returns earned by the global winner portfolio.

Table 1: Performance Statistics (1999 to 2009)

\begin{tabular}{|c|c|c|c|}
\hline \multicolumn{4}{|c|}{$\begin{array}{ll}\text { Panel A } & \text { Basic Performance Statistics } \\
\end{array}$} \\
\hline & MSCI World & Winner & $\underline{\text { Loser }}$ \\
\hline Return & $0.31 \%$ & $\overline{1.45 \%}$ & $\overline{1.87 \%}$ \\
\hline Std. Deviation & $4.90 \%$ & $7.14 \%$ & $8.35 \%$ \\
\hline Beta Coefficient & 1.000 & 1.239 & 1.228 \\
\hline \multicolumn{4}{|c|}{ Panel B $\quad$ Risk-Adjusted Performance Statistics } \\
\hline \multirow{5}{*}{$\begin{array}{l}\text { Sharpe Ratio } \\
\text { Treynor Ratio } \\
\text { Jensen's Alpha }\end{array}$} & MSCI World & Winner & $\underline{\text { Loser }}$ \\
\hline & 0.063 & 0.204 & 0.224 \\
\hline & 0.003 & 0.012 & 0.015 \\
\hline & 0 & 0.009 & -0.001 \\
\hline & & [3.208] & [3.550] \\
\hline \multicolumn{4}{|c|}{ Panel C $\quad$ Fama and French (1993) 3-Factor Model Regression Results } \\
\hline \multirow{3}{*}{ Intercept } & MSCI World & Winner & $\underline{\text { Loser }}$ \\
\hline & -------------- & $\overline{0.009}$ & $\overline{-0.001}$ \\
\hline & & [2.402] & {$[-0.220]$} \\
\hline \multirow[t]{2}{*}{ b_Market Risk Premium } & -------------- & 1.239 & 1.228 \\
\hline & & [19.658] & [20.927] \\
\hline \multirow[t]{2}{*}{ b_SMB (Small Firm Effect) } & -------------- & 0.775 & 0.330 \\
\hline & & [4.568] & [2.089] \\
\hline \multirow[t]{2}{*}{ b_HML (Value Effect) } & -------------- & -0.950 & 0.803 \\
\hline & & {$[-6.823]$} & [6.197] \\
\hline
\end{tabular}

Figure 1 illustrates the time-series cumulative returns for the global winner and loser portfolios and the MSCI World Index. The examination of the cumulative returns for the MSCI Index (refer to the trend line marked by empty dots) defines the periods from January 2000 to December 2002 and from July 2007 to February 2009 as the downswings of the global economic cycle. On the other hand, the periods prior to January 2000, in-between January 2003 and June 2007 and after March 2009 are defined as the upswings of the global economic cycle. 
An examination of the performance of the global winner portfolio reveals that the global winner portfolio moves in tandem with the MSCI World Index with substantially higher volatility. The global winner portfolio also accumulates returns much faster than the global loser portfolio (refer to the black trend line) during the upswing of the economic cycle. The global loser portfolio (refer to the black trend line) appears to be resilient after the crash of the I.T. bubble in 2000 with substantial initial rebound after 2002. The quick substantial recovery of the global loser portfolio in early 2009 is also noted. The relative strengths of the initial recoveries after financial market turmoil for the MSCI World Index and the global winner and loser portfolio are highlighted in the circled areas in Figure 1.

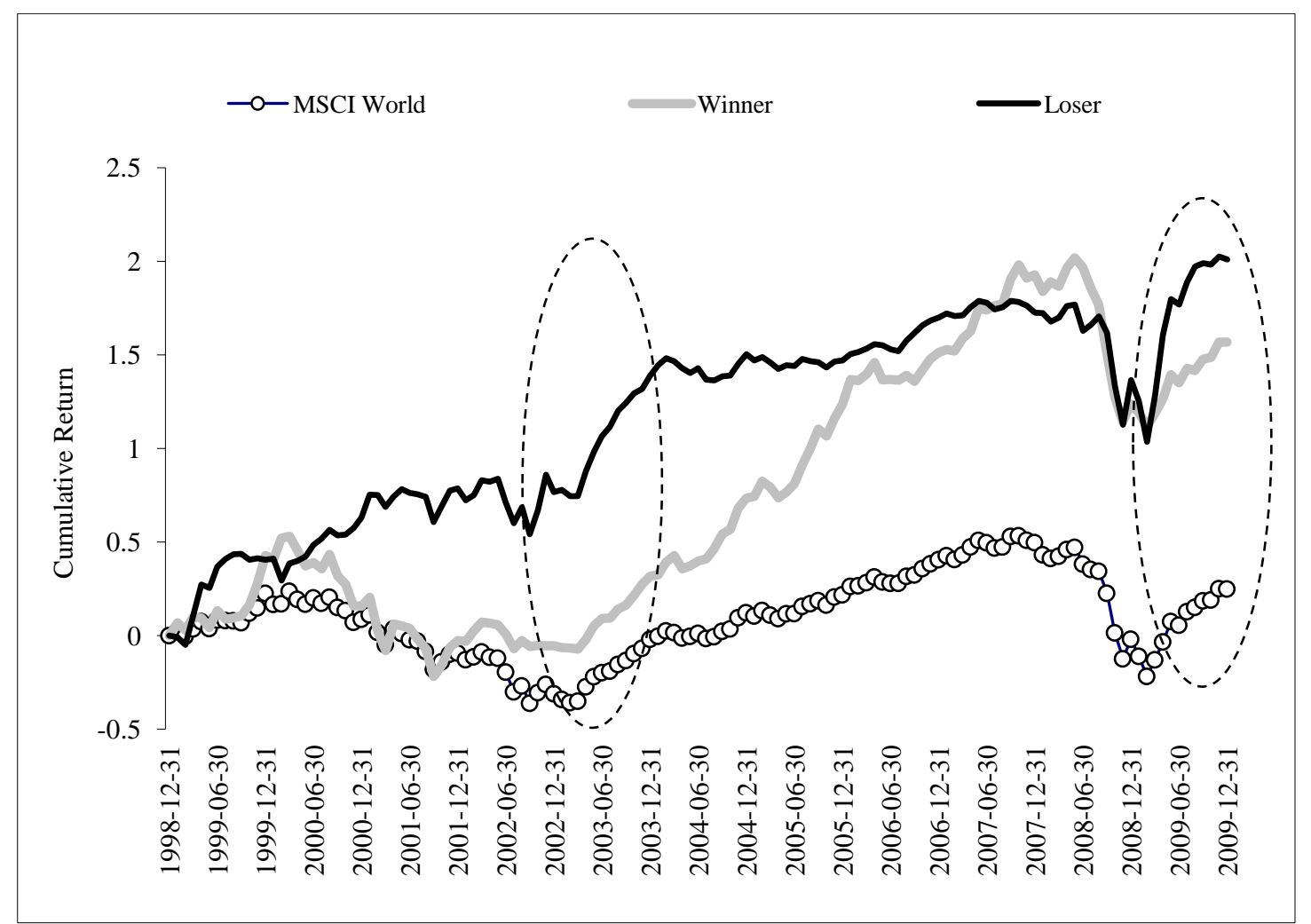

Figure 1: Performance of the Winner and Loser Portfolios (1999 to 2009)

The correlation matrix for the MSCI World Index, the global winner and loser portfolios and their respective residual returns is demonstrated in Table 2. Panel A of Table 2 displays the correlation coefficients between the MSCI World Index returns, the global winner portfolio returns and the global loser portfolio returns. The correlations of the residual returns between the respective portfolios based on the CAPM are demonstrated in Panel B of Table 2. The correlations of the residual returns between the respective portfolios based on the 3-factor model of Fama and French (1993) are demonstrated in Panel C of Table 2.

Examining the correlation coefficients of the monthly returns displayed in Panel A indicates that both the returns of the global winner and loser portfolios are highly correlated with the MSCI World Index ( 0.83 and 0.81 respectively). However, the correlation coefficient between the global winner and loser portfolio returns is only 0.48. In line with the result of Hsieh and Hodnett (2011), the correlation coefficient between the global winner and loser residual returns is significantly negative in both Panel B and Panel C ( -0.55 based on the CAPM residuals and 0.52 based on the Fama and French residuals). This finding indicates that the global winner portfolio outperforms the market when the global loser portfolio underperforms the market and vice versa. Since the residual returns of the global winner and loser portfolios are derived from the regression residuals of the CAPM, they are not correlated with the returns of the MSCI World Index. 
Table 2 Correlation Matrix (1999 to 2009)

\begin{tabular}{|c|c|c|c|}
\hline \multicolumn{4}{|c|}{ Panel A $\quad$ Correlations Based on Returns } \\
\hline & MSCI World & Winner & $\underline{\text { Loser }}$ \\
\hline MSCI World & 1 & & \\
\hline Winner & 0.83 & 1 & \\
\hline Loser & 0.81 & 0.48 & 1 \\
\hline \multicolumn{4}{|c|}{$\begin{array}{ll}\text { Panel B } & \text { Correlations Based on CAPM Residual Returns }\end{array}$} \\
\hline & MSCI World & Winner Residual & Loser Residual \\
\hline MSCI World & 1 & & \\
\hline Winner Residual & 0.00 & 1 & \\
\hline Loser Residual & 0.00 & -0.55 & 1 \\
\hline \multicolumn{4}{|c|}{ Correlations Based on Fama and French (1993) 3-Factor Model Residual Returns } \\
\hline & MSCI World & Winner Residual & $\underline{\text { Loser Residual }}$ \\
\hline MSCI World & 1 & & \\
\hline Winner Residual & 0.00 & 1 & \\
\hline Loser Residual & 0.00 & -0.52 & 1 \\
\hline
\end{tabular}

The results of the risk-return characteristics, time-series performances and correlation matrices indicate that the global winner and loser portfolios perform differently during different stages of the global economic cycle, have different strengths of initial recoveries from global financial crises and outperform the market at different times. All these findings suggest that the timing of equity mean reversion in the global equity market is in line with global economic cycles as investor sentiment and future prospects change.

Figure 2 depicts the mean reversion timing using the log winner-loser spread and the log cumulative residual returns of the global winner and loser portfolios based on the CAPM residuals over the examination period. The cumulative residual returns calculated based on the 3-factor model of Fama and French (1993) are illustrated in Figure 3. The negative correlation between the global winner and loser residual returns is reassured by examining the $\log$ cumulative residual returns of the two portfolios (refer to the trend lines).

The global winner and loser portfolios almost accumulate residual returns (that is, outperform or underperform the market) in opposite directions at all times. The fact that the log cumulative winner-loser spread (refer to the histograms in Figure 2 and Figure 3 ) is consistently below zero highlights the two market crashes that impede the global equity market performances over the examination period, as the global loser portfolio outperforms the global winner portfolio mainly during turbulent times and in the initial recoveries from the market crash. 


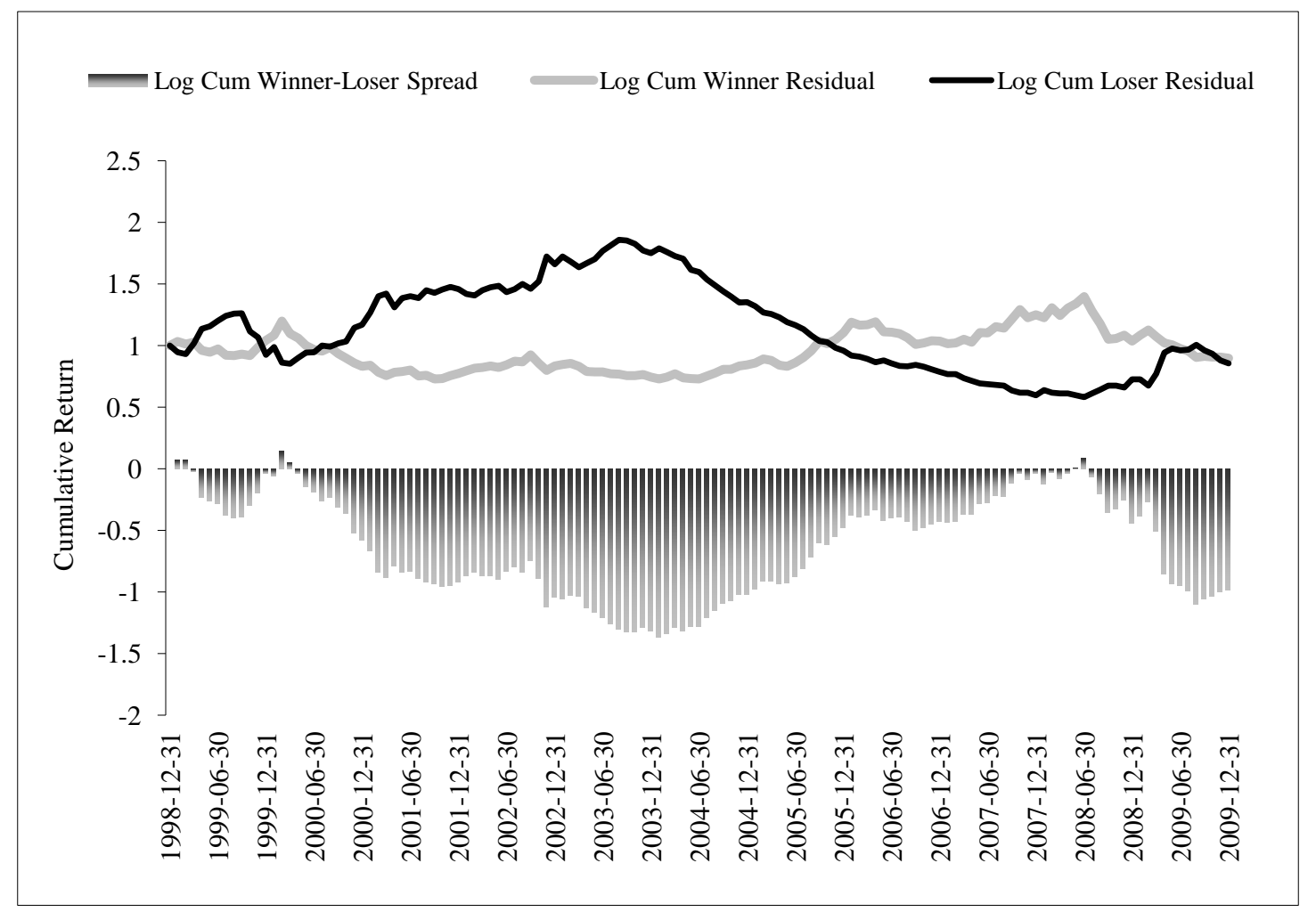

Figure 2: The Timing of Mean Reversion and the Global Economic Cycle (1999 to 2009): Analysis Based on the Residual Returns of the Capital Asset Pricing Model (CAPM)

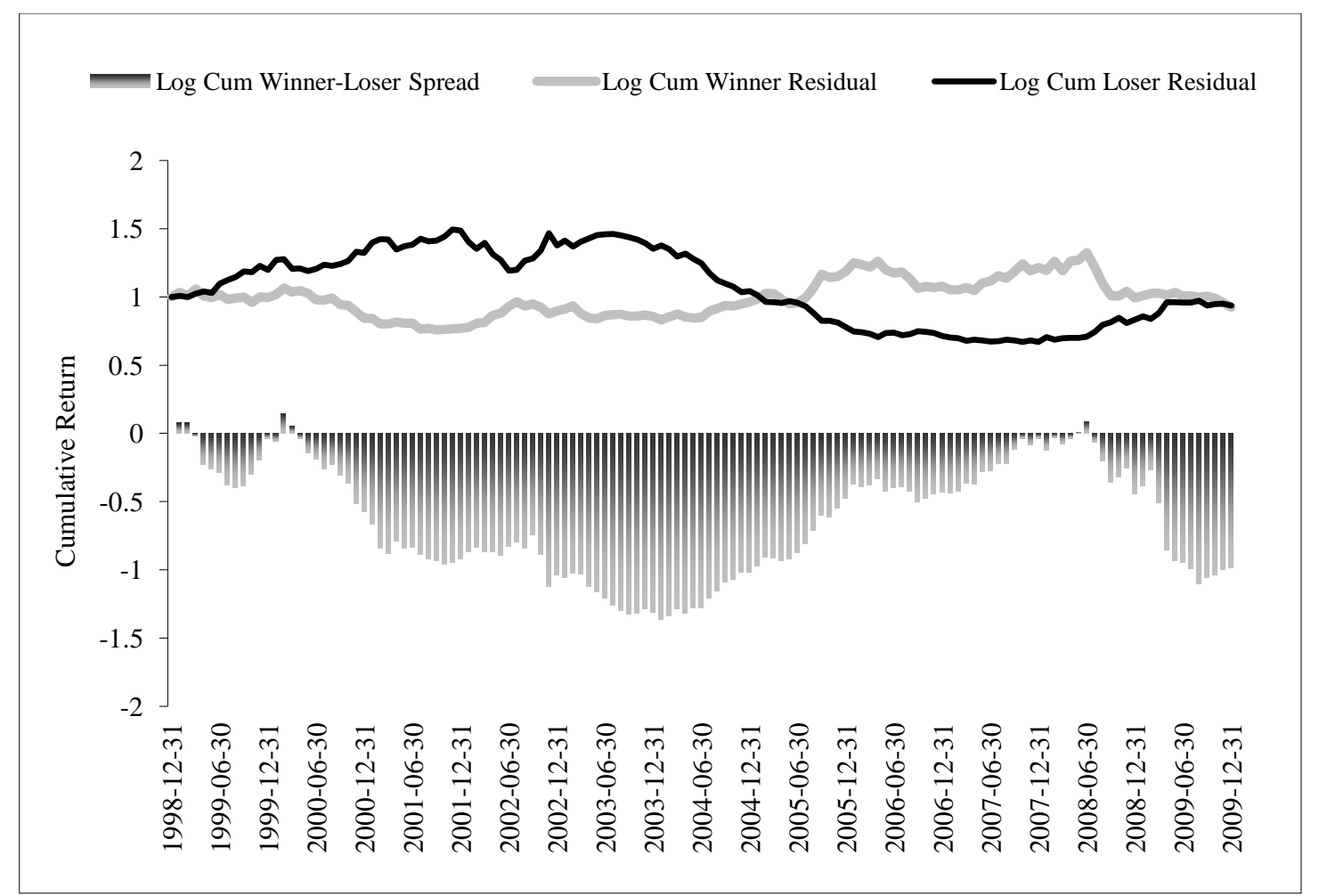

Figure 3: The Timing of Mean Reversion and the Global Economic Cycle (1999 to 2009): Analysis Based on the Residual Returns of the 3-Factor Model of Fama and French (1993) 


\section{CONCLUSION}

We constructed the global winner and loser portfolios based on prior 36-month returns over a 132-month period from 01 January 1999 to 31 December 2009. The fluctuations in the economic cycle is highlighted by the peak and the crash of the I.T. bubble in the early 2000s; the subsequent recovery and the upswing of the economic cycle from 2003 to mid-2007; the crash of the financial market in 2008 as a result of the sub-prime crisis; and the start of the recovery in early 2009.

The results of the performance statistics indicate that both winner and loser portfolios outperform the MSCI World Index on a risk-adjusted returns basis over the examination period. The risks associated with investing in the past long-term winners and losers are substantially higher than investments in average securities (in the market) in terms of both the standard deviation and beta coefficient measures. The fact that the beta coefficients for the global winner and loser portfolios are substantially higher than the market proxy and different from each other implies that abnormal returns calculated by simply subtracting the market return from the portfolio return is biased. This result supports the use of the residual returns computed from asset pricing models as proxies for abnormal returns and to take into account different degrees of sensitivity of the winner and loser portfolio returns to fluctuations in the market proxy returns.

When the returns of the global winner and loser portfolios are regressed on the market risk premium alone based on the CAPM, both portfolios earn abnormal returns (proxied by Jensen's alpha) that cannot be explained by the CAPM. When the proxies for the small firm effect and the value effect are added to the model, it is found that the abnormal returns earned by the global winner portfolio remains significant, but the abnormal returns for the global loser portfolio dissipates. This suggests that the abnormal returns to the global winner portfolio remains an efficient market anomaly after the value and size effects are considered as priced risks in the 3 -factor model of Fama and French (1993). Overall, all three factors contribute to the explanation of the variations in the global winner and loser portfolio returns. While all three factors are positively correlated with the global loser portfolio returns, the returns on the global winner portfolio is found to be negatively correlated to the value effect.

Although the global winner and loser portfolio returns are both strongly positively correlated with the MSCI World Index returns, the positive correlation between the global winner and loser portfolio returns is weak. The correlation coefficients between the global winner and loser portfolio residual returns computed from both the CAPM and the 3-factor model of Fama and French (1993) are significantly negative, indicating that the global winner and loser portfolios outperform the market at different times. This result is confirmed by examining the log cumulative residual returns of global winner and loser portfolios in that the two portfolios virtually accumulate residual returns in an opposite manner over the examination period. The log cumulative global winner-loser spread indicates that the global winner portfolio is outperformed by the global loser portfolio mainly during turbulent times and in the initial stage of the recovery phase after the financial market crises.

Overall, the study results are in support of the findings of Hsieh and Hodnett (2011) in that there exists a specific timing for the mean reversion of global winner and loser portfolios. The timing of mean reversion is found to be in line with changing investor sentiments and future prospects throughout the global economic cycle. The strength of the mean reversion is found to be strong during turbulent times when investors are fearful but weak when investor confidence is high. As a result, investments in prior long-term losers are resilient during financial market turmoil. In addition, investors seem to aggressively acquire long-term losers during the initial stage of the recovery from global financial crises. Built on this insight, we recommend that further research be conducted on the profitability of relative strength strategies.

\section{ACKNOWLEDGEMENT}

This research is supported by the National Research Foundation (NRF) of South Africa. We thank the research office of the University of the Western Cape for their support. 


\section{AUTHOR INFORMATION}

Dr. Heng-Hsing Hsieh, CFA is the Head of Finance in the School of Business and Finance at the University of the Western Cape, South Africa. He is a CFA charterholder and a member of the South African Institute of Financial Markets (SAIFM). E-mail: ahsieh@uwc.ac.za. Corresponding Author.

Dr. Kathleen Hodnett is currently a Research Fellow (funded by the National Research Foundation (NRF) of South Africa) in the School of Business and Finance at the University of the Western Cape, South Africa. She is a member of the International Institute of Forecasters (IIF) and an associate member of the South African Institute of Financial Markets (SAIFM).

\section{REFERENCES}

1. Baca S P, Garbe B L and Weiss R A (2000), “The Rise of Sector Effects in Major Equity Markets”, Financial Analysts Journal, vol 56, no 5, 34-40

2. Chan K C (1988), "On the Contrarian Investment Strategy”, Journal of Business, vol 61, no 2, 147-163

3. Chopra, N., Lakonishok, J. and Ritter, J. R. (1992) "Measuring Abnormal Performance - Do Stocks Overreact?", Journal of Financial Economics, vol 31, 235-268

4. De Bondt, W. F. M. and Thaler, R. H. (1985), "Does the Stock Market Overreact?", Journal of Finance, vol 40, no 2, 793-8055.

5. De Bondt W F M and Thaler R H (1987), "Further Evidence on Investor Overreaction and Stock Market Seasonality", Journal of Finance, vol 42, no 3, 557-581

6. Exley C J, Smith A D and Wright T (2004), Mean Reversion and Market Predictability, Stable Inn Actuary Society

7. Faber M T (2009), “A Quantitative Approach to Tactical Asset Allocation”, The Journal of Wealth Management, 1-47

8. $\quad$ Fama E F (1965), "The Behavior of Stock Market Prices”, Journal of Business, no 38, 34-105

9. Fama E F (1970), "Efficient Capital Markets: A Review of Theory and Empirical Work", Journal of Finance, no 25, 383-417

10. Fama E F (1991), “Efficient Capital Markets: II”, Journal of Finance, vol 46, no 5, 1575-1617

11. Fama E F and French K R (1992), "The Cross-Section of Expected Stock Returns", Journal of Finance, vol 47, 427-465

12. Fama E F and French K R (1993), "Common Risk Factors in the Returns on Stocks and Bonds", Journal of Financial Economics, vol 33 no 1, 3-56

13. Forner C and Marhuenda J (2003), "Contrarian and Momentum Strategies in the Spanish Stock Market Seasonality", Journal of Finance, vol 42, no 3, 557-581

14. Hodnett K (2010), "Analysis of the Cross-Section of Equity Returns on the JSE Securities Exchange based on Linear and Nonlinear Modelling Techniques", Unpublished Doctoral Thesis, University of Cape Town

15. Hsieh H (2010), "Applications of Global Equity Style Indices in Active and Passive Portfolio Management", Unpublished Doctoral Thesis, University of Cape Town

16. Hsieh H and Hodnett K (2011), "Tests of the Overreaction Hypothesis and the Timing of Mean Reversals on the JSE Securities Exchange (JSE): the Case of South Africa", Journal of Applied Finance and Banking, vol 1, no 1, 107-130

17. Muller C (1999), "Investor Overreaction on the Johannesburg Stock Exchange", Investment Analysts Journal, no 49, 5-17

18. Mutooni R and Muller C (2007), "Equity Style Timing", Investment Analysts Journal, no 65, 15-24

19. Nofsinger J R (2005), The Psychology of Investing, $3^{\text {rd }}$ Edition, Prentice Hall

20. Oldham G and Kroeger J A (2005), "Performance, Persistence and Benchmarks of Selected South African Unit Trusts for the Period 1998-2002", South African Journal of Business Management, vol 36, no 4, 81-90

21. Page M J and Way C V (Summer 1992/1993), "Stock Market Overreaction: The South African Evidence", Investment Analysts Journal, no 36, 35-49

22. Schiereck D, De Bondt W F M and Weber M (1999), "Contrarian and Momentum Strategies in Germany", Financial Analysts Journal, vol 55, no 6, 104-116 
23. Van Rensburg P (2001), “A Decomposition of Style-Based Risk on the JSE”, Investment Analysts Journal, no 54, 45-60

24. Van Rensburg P and Robertson M (2003a), "Style Characteristics and the Cross-Section of JSE Returns", Investment Analysts Journal, no 57, 1-10

25. Van Rensburg P and Robertson M (2003b), “Size, Price-to-Earnings and Beta on the JSE”, Investment Analysts Journal, no 58, 1-11 


\section{NOTES}

